\author{
Liz Yeomans* \\ Martina Topic ${ }^{* *}$
}

\title{
Engagement and Empathy Discourses in Corporate Communication: The Case of "The Science of Engagement"
}

\begin{abstract}
This paper analyzes engagement and empathy discourse in a corporate document The Science of Engagement published online by a leading UK PR agency. The method used was a critical discourse analysis (CDA) of the document, and the findings reveal that the engagement discourse in this document positions the consumer as a passive, compulsive purchaser, while the empathy discourse largely frames the consumer as young and more empathic than previous generations, and thus an easily accessible target for brands to appeal to, using emotional communication on social media. The conclusion of the paper is that in contrast to conceptual understandings of engagement as two-way and empathy as other-oriented, the Agency relies on early understanding of engagement as a cognitive process based on instincts and persuasive communication, and not as a concept of social communication that will be dependent on cultural and social differences, individual approach, and trust. This practice goes against the already acknowledged view of engagement and empathy as more than just cognitive responses by consumers, and presents an outdated understanding of these increasingly debated concepts.
\end{abstract}

Keywords: engagement, empathy, public relations, discourse

\section{Introduction}

The concept of engagement seems to be inherent to all communication professions at the moment; however, it is not always clear whether scholars or practitioners understand the term properly (Bortree \& Seltzer, 2009; Kang, 2014; Taylor \& Kent, 2014; 2002). Yet, it has become almost a buzzword in communications, marketing and advertising. Engagement is usually seen as a two-way communication but the confusion arises as to whether communication on social media platforms such as Twitter and Facebook can be considered as engagement or simply some sort of conversation and/or feedback (Adams \& McCorkindale, 2013; Kang, 2014; Lovejoy et al, 2012), and whether engagement encompasses much more than just a conversation, i.e. research, understanding, spending time together, dialogue, etc. (Taylor \& Kent, 2014) as well as an emotional connection (Johnston, 2014).

On the other hand, the turn to emotion in the academy, including cultural studies (e.g. Ahmed, 2007), organization studies (e.g. Bloch, 2012; Fineman, 2010; Putnam \& Mumby, 1993 ) and the social sciences (e.g. Greco \& Stenner, 2008; Turner \& Stets, 2005) is widely acknowledged. An interest in emotion, and empathy in particular, is also reflected in popu-

* Leeds Beckett University, Leeds, United Kingdom; 1.yeomans@leedsbeckett.ac.uk.

** Leeds Beckett University, Leeds, United Kingdom; M.Topic@leedsbeckett.ac.uk. 
lar discourse: numerous book titles espouse empathy as a core skill to provide competitive advantage in a global economy (Pedwell, 2012) while New Scientist magazine reports on technological innovation in the form of "empathy apps" to help workers strengthen their online and offline relationships (Rutkin, 2015).

In the light of a turn to engagement and emotion in the academy, as well as in popular discourse, this paper examines engagement and empathy discourse in a corporate engagement document. Using critical discourse analysis (CDA), we analyze engagement and empathy discourse of The Science of Engagement document published online by one of UK's leading PR agencies, Weber Shandwick.

\section{Public Relations and Engagement}

Engagement is a concept largely used in public relations (PR), marketing and communications in general. Engagement is often seen as something that can bring "positive organizational or marketing outcomes such as increased employee voluntary behaviours, consumer advocacy, financial support, and loyalty" (Kang, 2014, p. 399). However, the fact the concept is often used does not mean it is used in the right context, nor that all who use the term understand it properly (Bortree \& Seltzer, 2009; Kang, 2014; Taylor \& Kent, 2014; 2002).

Nevertheless, some authors have argued that engagement is an ideograph that many use without explaining what they mean when they say engagement, with which this term becomes a rhetorical argument that closes any discussion rather than fostering it (Taylor \& Kent, 2014). At first, the concept appeared in discussions on "importance of cognitive involvement for campaign related behavioural outcomes", and then again later on in "the context of community capacity building" (Johnston, 2014, p. 381). Recently, however, engagement became intertwined with Public Relations practice, as it is believed engagement presents the mantra for successful PR (Edelman 2008, cited from Johnston, 2014). Heath (2014) has argued that engagement is more than a two-way communication, but also an "appreciation for, and commitment to dialogue with and among stakeholders and organizations as community-building discourse and power resource co-management" (cited from Johnston, 2014, p. 382). Thus, engagement as a two-way communication has stepped in as a theory that has the power to replace the widely exploited Excellence theory that was a dominant paradigm in PR research for decades (Taylor \& Kent, 2014).

So far, however, engagement has been used in five communication contexts, i.e. "social media engagement, employee engagement, CSR and engagement, civic engagement and social capital, and dialogic engagement" (Taylor \& Kent, 2014, p. 385). In other words, many authors have explored the influence of social media such as Facebook, Twitter and others for fostering engagement and a two-way communication (Adams \& McCorkindale, 2013; Kang, 2014; Lovejoy et al., 2012), engagement in the workplace through exploring staff satisfaction (Men, 2012), CSR policies as an engagement with publics (Devin \& Lane, 2014; Golob \& Bartlett, 2007; O'Byrne, 2014; Men \& Tsai 2014; Tench et al., 2014), engagement and its role in building social capital (Taylor \& Kent, 2014), and engagement as a dialogue (Kent \& Taylor, 2002).

Engagement is closely related to caring for those stakeholders that PR practitioners communicate with, and in this way engagement has always been closely related to dialogue and a two-way communication rather than a one-way form of communication. However, in order 
to have a dialogue it is important that two sides of the communication process trust each other. Taylor and Kent (2014) argue that interaction between companies and customers on social media networks is not an example of dialogue but an exchange of information and feedback because a true dialogue must encompass more than just any conversation, i.e. "dialogue is only possible when people spend time together interacting, understanding the rules of interaction, trusting the other person/people involved in an interaction, etc." (p. 390).

This furthermore means that organizations who want to truly enforce engagement as part of their policy should understand engagement as an "interaction with stakeholder/publics to begin only after secondary research has been conducted to understand an issue(s), key publics, cultural variables, etc."; "demonstration of positive regard for stakeholder/publics' input, experiences and needs"; "interaction with stakeholder/publics for relational purposes, outside of an immediate problem/issue"; "interaction with stakeholder/publics for their advice and counsel on issues of organizational/public/community concern", and "interaction that contributes to a fully functioning society whereby organizations and publics recognize their interdependence and act together for the good of the community" (Taylor \& Kent, 2014, p. $391)$. On the other hand, according to Kang (2014, p. 403) the elements of engagement are trust, satisfaction, word of mouth and loyalty.

In sum, engagement is about building relationships with stakeholders. However this relationship needs to be a two-way communication grounded in research, trust and understanding and not just as a way of initiating conversations and feedback sessions. This also means that PR practitioners who seek establishing engagement with publics need to understand their publics and their needs and find a way to engage them, rather than just communicate with them via communication channels. This is because even though communication channels such as social media present some sort of conversation and communication, they still do not present a dialogue or engagement because engagement is more than just a conversation and communicating with publics via social media or other communication channels presents a type of one-way communication, or at least a one-way initiation of conversation but not engagement that primarily needs to be built on trust and understanding.

\section{Empathy in Public Relations}

Within the public relations literature, empathy is considered as important to achieving an organization's communications objectives. Here, empathy is discussed as a key principle, an interpersonal process, and a personal trait, attribute or competence. Empathy is a key principle in engaging publics, providing an "atmosphere of support and trust that must exist if dialogue is to succeed" (Kent \& Taylor, 2002, p. 27) and building organization-public relationships (Bruning, Dials, \& Shirka, 2008). Empathy is regarded an important part of an organization's response in crisis communication (Martinelli \& Briggs, 1998; Seeger, 2006) and there are attempts to measure empathy as part of "personalizing" organization-publics relationships (e.g. Bruning, Dials, \& Shirka, 2008, p. 29).

Windahl and Signitzer (1992, p. 21) explore empathy more conceptually. These authors define empathy as: "the capacity to understand how other people perceive and interpret reality $[\ldots]$ without giving up one's own view of this reality". Empathy, along with the related concept of social perspective-taking, which is "the ability to understand the options available to others", are considered important interpersonal processes for the communication planner 
who often has "no direct contact with the people with whom they communicate" (Windahl \& Signitzer, 1992, pp. 21-22). These authors go on to hint at the problems of disparities, or dissimilarities, between sender and receiver in communication, citing social perspective-taking (Reardon, 1987) as particularly helpful in attempting to address these disparities.

Another concept closely related to empathy, is that of role-taking (Mead, 1934) which Culbertson (2009, p. 3) defines as the process of "psyching out", understanding, or predicting another's attitudes, behaviors, and points of view". Culbertson's definition of role-taking clearly points to a self-orientated (Coplan, 2011), even manipulative, version of empathy, which he argues is important for PR practitioners to focus on (i.e. identify, measure and control). Described in this way, role-taking, like social perspective-taking, is a form of empathy, but there is no suggestion that the actor lets go of the self and engages with the "other" through feeling (Calloway-Thomas, 2010) - rather, the practitioner retains full, cognitive control standing back to observe the minutiae of their role-taking interactions with the other person and its effects.

Jin (2010), meanwhile, explicitly examined emotion in public relations leadership and employee communication. In contrast to the foregoing views of empathy as a key principle and an interpersonal process, Jin's study, identified empathy as a core emotional trait, attribute and communication competence of a PR leader. Empathy, according to Jin (2010, p.179), enables leaders to both assess employees' emotions and respond to them "with sensitivity and understanding". Empathy also enhances PR leaders' communication effectiveness with top management. Finally, a recent qualitative study identified empathy as among the top three personal attributes in four specific professional communication roles, further highlighting the perceived importance of empathy among public relations practitioners (Tench \& Moreno, 2015).

While the importance of empathy as a personal attribute or competence for public relations practitioners has emerged from recent studies (i.e. Jin, 2010; Tench \& Moreno, 2015), there is little scholarly attempt to conceptualize empathy in PR, nor is there interest in the broader, neoliberal discourse(s) of empathy and its implications for PR's relationships with the market/consumers, as discussed by political scholars such as Pedwell $(2014 ; 2012)$ and Olsen (2013). Therefore it is necessary to provide broader frameworks from the social sciences for discussing empathy including "self" and "other" orientation (Calloway-Thomas, 2010; Coplan, 2011); "true" and "instrumental" empathy (Pedwell, 2012).

\section{Method}

For this research, we analyzed one major corporate document published online by one of the leading PR agencies in the UK, entitled The Science of Engagement: An exploration into the true nature of engagement-what it means and what causes it. Grounded in science, not fiction (Canvas 8/Weber Shandwick, 2014). In this document, which we classify as a "corporate positioning document" due to its persuasive content, the Agency offered views on what constitutes engagement and empathy, and how their work is built on engagement. In order to understand what the Agency is trying to achieve we conducted a critical discourse analysis of the document to determine what is the ideological/relational positioning of this organization and in which way they would like to shape society?

In our analysis we looked for the so-called "discursive topoi" as defined by Ruth Wodak (1999). Wodak defined "discursive topoi" as a "core argument that appears in the talk of the 
actors" (Wodak 1999, cited from Topic \& Vasiljevic, 2011, p. 4). In keeping with Wodak's emphasis on the dialectical relationship between discourses and specific fields of social action, we locate the discourses identified within the social and institutional contexts within which they are embedded (i.e. business/the market), therefore, the findings are analyzed against the theoretical debates on engagement and empathy in PR as well as in the broader literature on empathy.

In the analysis, we focused on the Principles of Engagement section, and on empathy as one of 19 elements of engagement. The reason for focusing on empathy only is that, apart from defining 10 principles of engagement, the Document also defines 19 elements of engagement by introducing terms such as "access", "aesthetics", "associations", "belonging", "desire", "empathy", "enhancement", "escape", "escape", "experience", "herd behaviour", "integrity", "intrigue", "involvement", "meaning", "newness", "pleasure", "respect", "shared values", and "social totems" (The Science of Engagement, Canvas 8/Weber Shandwick, 2014, pp. 10-12). Each of these elements could be a subject of special analysis since they were analyzed separately by scholars working in those fields, and this prevents detailed analysis of each element in this paper due to the limited space. However, the Document makes reference to the emotions and since empathy is a concept intertwined with emotions (Calloway-Thomas, 2010; Clark, 1997), we decided to conduct a discourse analysis of the 10 Principles of Engagement, and then an in-depth analysis of the Document understands of empathy.

\section{Findings}

"The study of the reproduction of power and dominance through discourse is a primary objective" as it is considered critical discourse analysis (van Dijk, 2008 p. 84). In this document the overarching discourse of science pervades, framing engagement through claims to specific expertise represented by a panel of three scholars (defined as "Methodology") contributing expert knowledge in anthropology, psychology, behavioral economics and neuroscience (The Science of Engagement, Canvas 8/Weber Shandwick, 2014, p. 15). The discourse of science encompasses the visual design of the document, from a genetic structural diagram on the front cover to the 19 elements of engagement (p. 9), which are represented through an emulation of the periodic tables in chemistry. The rhetorical power of what may be termed as popular scientific discourse could be said to legitimize the claims concerning the central topic of engagement.

\section{The Engagement Discourses}

We identified two main discourses of so-called engagement, i.e. the discourse of a passive consumer and the discourse of consumers as impulsive buyers. These two discourses form the core understanding of engagement as understood by The Science of Engagement Document, and these two discourses appear as core arguments why companies should "engage" in the way the Agency proposes. 


\subsection{The discourse of a passive consumer}

The discourse of a passive consumer is strongly present in the Document through a variety of explanations the Agency offers about consumers. It appears that engagement is understood through profit orientation and business growth, or stimulated purchase, which corresponds with views of engagement in the early days when the concept was firstly introduced (Kang, 2014). In addition, engagement is understood through emotional connections, and this connection is particularly seen as present on social media:

Engagement requires an emotional connection between a brand or organisation and an individual. This emotional connection leads to action, whether purchases, shares, Likes or Tweets, which are measured as participation. Because engagement is relative, its intensity can be measured by the strength of an individual's connection or participation. (The Science of Engagement, Canvas 8/Weber Shandwick, 2014, p. 6).

Treating consumers as passive recipients of messages makes this definition diametrically opposite to the definition of engagement by PR scholars working in the field who state that engagement is not an online conversation or online feedback sessions, but a continuous effort that comes from both sides and must be built on trust (Taylor \& Kent, 2014). In addition, engagement defined like this assumes digital media as the most crucial mean for engagement (in any understanding), which goes directly opposite against the current media research showing that even though digital media has risen, this rise does not undermine the importance of the traditional media that remain strong in setting the agenda since the early days of communication research (Barnes et al., 2008; Breed, 1955; Dearing \& Rogers, 1996; Hamilton, 2004; Kim et al., 2015; Lee et al., 2005; Ofcom, 2014; McCombs, 2004; 2014; Messner \& WatsonDistaso, 2008; Manheim \& Albritton, 1984; Roberts et al., 2002, Tan \& Weaver, 2013; Weiss, 1974; Winter \& Eyal, 1981).

In addition, research shows that even though millions of people use digital media, it is still only one part of the population that does so, usually the younger and better educated part, while other members of societies still remain loyal to traditional media (Figenschou et al, 2015; Ofcom, 2014; Salwen et al, 2005). Also, new digital media are quoting traditional media much more than the other way around, which means that it is still the traditional media that set the public agenda (Barnes et al., 2008; Breed, 1955; Dearing \& Rogers, 1996; Hamilton, 2004; Kim et al., 2015; Lee et al., 2005; Ofcom, 2014; McCombs, 2004; 2014; Messner \& Watson Distaso, 2008; Manheim \& Albritton, 1984; Roberts et al., 2002, Tan \& Weaver, 2013; Weiss, 1974; Winter \& Eyal, 1981). Turning only to consumers who "engage" online actually means turning to a very specific part of the market, while ignoring others.

It appears that the Agency is trying to re-position itself in the PR market in line with the new trend of abandoning the Excellence theory of PR and turning towards engagement without actually understanding what it means to engage (Taylor \& Kent, 2014; 2002; Kang, 2014; Bortree \& Seltzer, 2009), and probably without even being aware of any PR theory or Media theory. The lack of understanding is particularly visible in additional elements of engagement where consumers are treated as objects that need to be persuaded to engage, i.e. again as passive recipients of communication messages. This is similar to the long abandoned hypodermic needle theory of communication effects of the mass media that treated audiences as patients and media messages as drugs (Haralambos \& Holborn, 2000; McCombs, 2004; 2014) as well as psychological theories of persuasive communication where people were seen as easy targets for persuasion via media messages (Petty et al., 2009). For example, the doc- 
ument states that, "engagement is a finite resource, not an infinite commodity" (The Science of Engagement, 2014, p. 6). In elaboration of this view, the document correctly states that people's attention is limited, which has been recognized in both PR and CSR work (Pederson, 2006). However, the document then continues by stating.

Brands must be realistic about what they demand from people and clear in communicating what people can expect in return. Different environments pose different challenges for engagement - whether at home or on-the-go, alone or with friends, at night or in the morning. Knowledge of these factors will help brands identify the most relevant and opportune moments for engagement (The Science of Engagement, Canvas 8/Weber Shandwick, 2014, p. 6, our emphasis).

Nevertheless, the companies only need to capture attention and they will build engagement:

Like the special offer, communications can capture our attention. Shout loud enough and everyone will look. Keep shouting and you may go unheard. Combining novel ways to capture attention with audience resonance builds engagements. Next time, you won't have to shout so loud (The Science of Engagement, Canvas 8/Weber Shandwick, 2014, p. 7).

\subsection{Consumers as impulsive buyers}

Another discourse is the view of consumers as people who can easily be stimulated for purchase based on their subconscious desires and needs for immediate rewards, which clearly leads to impulsive behavior. For example:

Our brains process all decisions as potential rewards driven by two systems: what we want and what we like. Our wanting system (System One) is driven by subconscious desires. These decisions we call our 'gut feelings'. They are mental short cuts-instinctive, impulsive and often related to immediate and primal rewards, such as a piece of chocolate or sex [...] (The Science of Engagement, Canvas 8/Weber Shandwick, 2014, pp. 6-7).

Our brains have evolved to make snap decisions based on the anticipation of immediate reward. These decisions are not always conscious-consider System One thinking. Communications' call-to-action requires a direct connection to the reward. Rewards that are perceived as immediate deliver higher engagement (The Science of Engagement, Canvas 8/Weber Shandwick, 2014, p. 7).

The view of consumers as impulsive buyers is again in line with early research on engagement based on cognitive aspects of consumer behavior (Johnston, 2014) and not the new research taking in consideration engagement as a two-way process of communication built on trust (Taylor \& Kent, 2014) or even CSR Communication (Tench et al., 2014).

The Science of Engagement Document also explains decisions to eat take away food and watch the TV as a need coming from System One entirely ignoring, for example, the current situation in the market where people work long hours on frustrating zero hour contracts, and once when they return home they are unable to do anything else including cooking (see Bowman, 2015 and the discussion in the comments section). However the Document states this:

People are often unaware of the reasons behind their decisions. When they pledge to get healthy, save money or learn more, they are demonstrating System Two engagement. Later, when they are tired and grab fast food before collapsing in front of the television, the primitive urge of System One takes over. People say to themselves 'I deserved it', and that 'tomorrow I'll restart the diet' (The Science of Engagement, Canvas 8/Weber Shandwick, 2014, pp. 6-7). 
Nevertheless, passive consumers apparently can be stimulated to engage with brands by offering them rewards such as coupons and similar sales promotions:

Those seeking high engagement must offer a high reward. This can be a tangible reward, such as a voucher, but can also be a softer, more long-term reward, such a sense of belonging, self-actualisation or status. Softer rewards are adaptable, allowing audiences to serve their personal needs. This requires an understanding of the common ground between the individual's goals and the brand or organisation's goals (The Science of Engagement, Canvas 8/Weber Shandwick, 2014, p. 6).

This again goes against views of scholars working in the field of engagement who said that engagement must be a two-way communication built on trust and common goals, i.e. to work together for the betterment of the community, and engagement is built on elements such as primarily secondary research of culture and identifying the key publics, treating customers as equal in building joint policies and community programmes and accepting their advice, acting together, etc. (Taylor \& Kent, 2014). But contrary to these views, The Science of Engagement document enforces a view according to which companies only have to decide to engage with customers, and this will be accomplished:

Engagement is not a light to be switched on or off within people. It shines all the time, varying in intensity from person to person, time to time, and context to context. Whether brands choose to acknowledge it or not matters less. How and when they choose to capitalise on the right types of engagement across various channels and topics is the real issue (The Science of Engagement, Canvas 8/Weber Shandwick, 2014, p. 6).

If we put aside the PR theories, the views expressed in this document are also going against all sociological theories emphasizing socialization and cultural values as crucial in our development as social beings, and this has an influence over our purchase behavior. Even though socialization is a process that lasts all life (Haralambos \& Holborn, 2000) it still needs a major effort to build trust and engagement, and the approach cannot be uniform. It seems, however, that the Agency still relies on understanding of engagement as it was present in the early days when this term was introduced in debates on managing publics, i.e. engagement is apparently understood as a means but not as an end to use Kant's term, and as a way to achieve consumer advocacy and loyalty (cf. Kang, 2014). The way the agency proposes to do this is based on early understanding of engagement as a cognitive involvement that affects consumer behaviour (Johnston, 2014).

\section{Empathy Discourse: Paradigm Shifts and Releasing Genies}

Empathy is listed as one of the 19 elements of engagement in the Document. It is defined as:

The ability to relate to another person's situation, feelings or experience is a fundamental human trait. Empathy is a subconscious process that builds engagement. In science: understanding or observing something engages the same neural structures as actually doing it. In action: caring about a film or story's protagonist (The Science of Engagement, Canvas 8/Weber Shandwick, 2014, p. 10)

Empathy is further expanded upon on page 16 when one of the experts, an anthropologist, Dr Grant McCracken, offers an "anthropological perspective". The text follows: 
Empathy is hard-wired into the human species. It is creating what anthropologists refer to as 'the death of difference'. Not very long ago, people saw groups that were different from their own as being slightly alarming or strange and threatening. You could persuade them without much difficulty to demonise those groups. Culture used to get in the way of people's natural mirroring process or empathy. Younger people are now thinking "Well, they're not that different. No-one's so different from me that I can't imagine what their lives are like; I can't participate in their lives from a distance. (The Science of Engagement, Canvas 8/Weber Shandwick, 2014, p. 16).

Empathy discourse in this text frames empathy in a number of ways. The first discourse is that it is a biological human trait, which also accords with the earlier definition in the "19 elements of engagement". The phrases "hard-wired", "natural mirroring process", "fundamental human trait" and "neural structures" reinforce the idea that empathy is something that people have or are naturally born with, thus fulfilling an individual, if rather limited, "container" view of emotion which arises from psycho-biological theories (Yeomans, 2013).

Very quickly, however, the discourse shifts: "it is creating [...] the death of difference" suggests that empathy is being put to use in some new way-to break down cultural barriers between people. "Not very long ago" suggests that people were unable to use their natural empathy, but now, they are able to. But, if empathy "is creating [...] the death of difference" now, why was it not doing this before, if indeed it is "hard-wired into the human species"? Further on in the text, the meaning becomes clearer as the word "people" is qualified by "younger". This raises the question of why "younger people" are more empathic than other generations who, we are told, allowed culture to "get in the way" and who could be persuaded to "demonise" others? The text continues:

Now the 'empathy genie' has been let out of the bottle, and now it's spreading everywhere. People are using it for new purposes, as a kind of experiential vehicle. They use it to imagine what it would be like to be a coffee grower in Guatemala. You can engage with people's empathy. Empathy means that people will follow you anywhere (The Science of Engagement, Canvas 8/Weber Shandwick, 2014, p. 16)

The reference to "genie" having been "let out of the bottle" is curious, suggesting that something bad has been allowed to happen that is irreversible: "it's spreading everywhere". And yet the suggested intention of the "genie" idiom is that something good has occurred as a result of the genie's release. The emphasis in this text is on the utility of empathy which is being deployed "for new purposes", by which we infer good purposes when we learn about how people use empathy to imagine the life of a "coffee grower in Guatemala" (e.g. evoking the image of Fairtrade). "You can engage with people's empathy" and "empathy means that people will follow you anywhere" suggests an instrumental orientation towards empathy, not forgetting that emotion here is ultimately used within engagement discourse as a resource to connect people to brands. From this text it is unclear why there has been a sudden release of empathy among human beings, and how this has happened, and is there truly evidence of it in the current world?

The next paragraph, which refers to identification, identity and media consumption, once again evokes the then ("we used to") and now discourse, implying that something new is occurring as a result of empathy, although again, we are not informed precisely why this is happening:

A wonderful English film critic recently said that in the old days we used to identify with the hero. Now, we identify with everybody on the screen - the hero, the villain, the bit players - we are voracious in this process of identification. So it's an incredibly powerful piece of engagement, to give people an opportunity 
for identity exploration, for identity definition and identity manufacture (The Science of Engagement, Canvas 8/Weber Shandwick, 2014, p.16).

The above text switches the discourse of empathy as "hard-wired" to empathy framed as an interactional process. Indeed the reference to "this process of identification" in relating the individual engaging with a cultural product-a film-brings in a socio-cultural understanding of empathy as feeling that is produced through interactions between the self and other (Calloway-Thomas, 2010). However, this identification process is ultimately put to individual use as an identity project: "identity exploration", "identity definition" and "identity manufacture". Furthermore, the rhetorical uses of "we": "we identify with everybody on the screen" and "we are voracious in this process of identification" makes claim to a societal shift, not just a (younger) generational shift in media consumption.

I think people are increasingly engaged by the idea that they are accomplishing some social good; they're still individuals, acting in a way that suits them and benefits them, but from that stems social good. Younger consumers in particular want to break out of the prison of individualism. (The Science of Engagement, Canvas 8/Weber Shandwick, 2014, p. 16)

The final paragraph is a discourse of defence: empathy here is not merely deployed to help the individual to explore, define and produce, or re-make, their own identity-a self-identity project, but to serve a higher social purpose. Once again, "younger" people; this time "younger consumers" are marked out as the people of particular interest. Breaking out of "the prison of individualism" is a powerful metaphor used to demonstrate that young consumers are not self-centred and self-serving but reaching out to achieve wider social goals.

\section{Conclusion}

From our analysis, it is obvious that the Agency relies on early understanding of engagement as a cognitive behaviour based on instincts and persuasive communication, and not as a concept of social communication that will be dependent on cultural and social differences, individual approach, and trust. People are seen as impulsive and easily manipulated, and clients only need to find the right way to stimulate them and they will give a "like" on Facebook or re-tweet something, and that automatically means customers are engaged and purchasing. In practice, it is very likely that liking or re-tweeting means nothing of the above, or at least not with all customers and for all companies.

The Document as The Science of Engagement claims to be scientific but it ignores findings from social sciences and relies almost entirely on findings from cognitive science, albeit even these findings are not referenced properly but rely merely on the three people who claim to be the experts. There is no relying on communication, media, PR, CSR, or sociology and findings and views from these disciplines, which is why this document does not offer a social understanding of engagement.

In other words, the document seems passé because many companies are nowadays turning towards socially responsible and relevant campaigns that engage people in joint causes and foster values of equality, diversity, address social problems such as obesity, etc. Examples of these campaigns are Always' campaign \#Like a Girl where the company tried to explain what it means to enforce stereotypes on young girls and how that affects growing up, 
or Morrison's Let's Grow Together where the company addressed concerns about obesity and unhealthy living, to see that companies are trying to engage and build trust with customers. Whether they are successful or not is another question, however, the attempt is apparent. On the other hand, those companies that do not launch large campaigns to create dialogues have turned to fostering social values and addressing changed social circumstances to appeal to their target customers but again by refraining from persuasive advertising (e.g. Chanel's campaign The One That I Want, which approached single mothers who are trying to balance work and private lives).

In common with the contradictions and problems that we have already identified, in which the consumer is positioned as passive, the discourse of empathy is also problematic. Rather than discussed as a key principle in building (long-term) dialogue and trust (Kent \& Taylor, 2002) and to engage publics (Bruning, Dials, \& Shirker, 2008), the empathy discourse in the Document could be described as instrumental (Pedwell, 2012) and self-orientated (Coplan, 2011).

In The Science of Engagement, the utilization of an empathy science discourse frames empathy (through unsupported generalizations and claims) as a freely available human trait or attribute, and thus a resource that can be captured and deployed to connect people, particularly young consumers, to brands through appealing to both their individualistic and social concerns as part of identity formation. From this discourse, we have no indication as to why there is more empathy leading to the "death of difference" (Canvas 8/Weber Shandwick, 2014, p. 16); indeed current world events would suggest the opposite is occurring: an "empathy deficit" as coined by President Barack Obama (cf. Pedwell, 2012, p. 280). However, our earlier analysis of engagement discourse and social media may provide some explanation as to why younger people are perceived to be able to overcome cultural differences, through empathy, better than older generations. This is compelling to brands because young consumers as voracious social media users are positioned as a ready-made target for brands to appeal to, using emotionally-charged communication strategies.

It would seem, then, from The Science of Engagement, that empathy is another resource that can be tapped into and released, just like the empathy app (Rutkin, 2015), to suit market demands. We therefore concur with critics that the deployment of engagement and empathy discourses within a business context must be problematized and critiqued to reveal their true intentions.

\section{References}

1. Adams, A., \& McCorkindale, T. (2013). Dialogue and transparency: A content analysis of how the 2012 presidential candidates used twitter. Public Relations Review 39, 357-359.

2. Ahmed, S. (2007). The cultural politics of emotion. London: Routledge.

3. Barnes, M.D., Hanson, C.L., Novilla, L.M.B., Meacham, A.T., \& McIntyre, E. (2008). Analysis of media agenda setting during and after Hurricane Katrina: Implications for emergency preparedness, disaster response, and disaster policy. American Journal of Public Health, 98(4), 604-610.

4. Bloch, C. (2012). Passion and paranoia. Emotions and the culture of emotion in academia. Farnham, Surrey, UK: Ashgate.

5. Bortree, D.S., \& Seltzer, T. (2009). Dialogic strategies and outcomes: An analysis of environmental advocacy groups' Facebook profiles. Public Relations Review 35(3), 317-319. 
6. Bowman, A. (2015). Stories from staff on zero hour contracts. Retrieved from: http://www.totaljobs .com/insidejob/stories-from-staff-on-zero-hour-contracts/.

7. Breed, W. (1955). Newspaper opinion leaders and the process of standardization. Journalism Quarter$l y, 32,277-284$.

8. Bruning, S.D., Dials, M., \& Shirker, A. (2008). Using dialogue to build organization public relationships, engage publics, and positively affect organizational outcomes. Public Relations Review, (34), 25-31.

9. Calloway-Thomas, C. (2010). Empathy in the global world: An intercultural perspective. Thousand Oaks: Sage.

10. Canvas8/Weber Shandwick (2014). The Science of Engagement. An exploration into the true nature of engagement-what it means and what causes it. Grounded in science, not fiction. Retrieved from: http://webershandwick.co.uk/what-we-do/.

11. Clark, C. (1997). Misery and company: Sympathy in everyday life. Chicago: University of Chicago Press.

12. Coplan, A. (2011). Will the real empathy please stand up? A case for a narrow conceptualization. The Southern Journal of Philosophy, 49, 40-65.

13. Dearing, J.W., \& Rogers, E.M. (1996). Agenda-setting, Vol. 6. Thousand Oaks: SAGE.

14. Devin, B.L., \& Lane, A.B. (2014). Communicating engagement in corporate social responsibility: A meta-level construal of engagement. Journal of Public Relations Research, 26, 436-454.

15. Van Dijk, T.A. (2008). Discourse and power. Basingstoke: Palgrave Macmillan.

16. Figenschou, T.U., Beyer, A., \& Thorbjornsrud, K. (2015). The moral police: Agenda setting and framing effects of a new(s) concept of immigration. Nordicom Review, 36(1), 65-78.

17. Fineman, S. (2010). Emotion in organizations - a critical turn. In B. Sieben \& A. Wettergren (Eds.), Emotionalizing organizations and organizing emotions (pp. 23-41). Basingstoke: Palgrave Macmillan.

18. Golob, U., \& Bartlett, J. L. (2007). Communicating about corporate social responsibility: A comparative study of CSR reporting in Australia and Slovenia. Public Relations Review, 33, 1-9.

19. Greco, M., \& Stenner, P. (2008). Introduction: emotion and social science. In M. Greco \& P. Stenner, (Eds.), Emotions: A social science reader (pp. 1-21). Oxford: Routledge.

20. Hamilton, J.T. (2004). All the news that's fit to sell: How the market transforms information into news. Princeton, NJ: Princeton University Press.

21. Haralambos, M. \& Holborn, M. (2000). Sociology: Themes and perspectives. London: Collins Educational.

22. Johnston, K.A. (2014). Public relations and engagement: Theoretical imperatives of a multidimensional concept. Journal of Public Relations Research, 26(5), 381-383.

23. Kang, M. (2014). Understanding public engagement: Conceptualizing and measuring its influence on supportive behavioural intentions. Journal of Public Relations Research, 26(5), 399-416.

24. Kent, M.L., \& Taylor, M. (2002). Toward a dialogic theory of public relations. Public Relations Review, 28, 21-37.

25. Kim, J.Y., Kiousis, S., \& Xiang, Z. (2015). Agenda building and agenda setting in business: Corporate reputation attributes. Corporate Reputation Review, 18(1), 25-36.

26. Lee, B., Lancendorfer, K.M., \& Lee, K.J. (2005). Agenda-setting and the internet: The intermedia influence of internet bulletin boards on newspaper coverage of the 2000 general election in South Korea. Asian Journal of Communication, 15(1), 57-71.

27. Lovejoy, K., Walters, R.D., \& Saxton, G.D. (2012). Engaging stakeholders through Twitter: How nonprofit organizations are getting more out of 140 characters or less. Public Relations Review, 38(2), 313-318.

28. Manheim, J.B. \& Albritton, R.B. (1984). Changing national images: International public relations and media agenda setting. The American Political Science Review, 78(3), 641-657.

29. McCombs, M. (2014). Setting the agenda: The mass media and public opinion ( $2^{\text {nd }}$ edition). Cambridge: Polity.

30. McCombs, M. (2004). Setting the agenda: The mass media and public opinion. Cambridge: Polity Press. 
31. Men, K.R., \& Tsai, W-H.S. (2014). Perceptual, attitudinal, and behavioral outcomes of organization-public engagement on corporate social networking sites. Journal of Public Relations Research, 26(5), 417-435.

32. Men, L.R. (2012). CEO credibility, perceived organizational reputation, and employee engagement. Public Relations Review, 38, 171-173.

33. Messner, M., \& Watson-Distaso, M. (2008). The source cycle: How traditional media and weblogs use each other as sources. Journalism Studies, 9(3), 447-463.

34. Obama, B. (2006). The audacity of hope: Thoughts on reclaiming the American dream. Crown/Three Rivers Press.

35. O'Byrne, S., \& Daymon, C. (2014). Irresponsible engagement and the citizen investor. Journal of Public Relations Research, 26(5), 455-473.

36. Ofcom (2014). Adults's media use and attitudes report 2014. Retrieved from: http://stakeholders .ofcom.org.uk/binaries/research/media-literacy/adults-2014/2014_Adults_report.pdf.

37. Olson, G. (2013). The neoliberal state and the state of empathy. In Empathy imperilled: Capitalism, culture and the brain (pp. 43-51).Springer Briefs in Political Science 10.

38. Pedersen, E.R. (2006). Making corporate social responsibility (CSR) operable: How companies translate stakeholder dialogue into practice. Business and Society Review, 111(2), 137-163.

39. Pedwell. C. (2014). Affective relations. The transnational politics of empathy. London: Palgrave Macmillan.

40. Pedwell, C. (2012). Economies of empathy: Obama, neoliberalism, and social justice. Environment and Planning D: Society and Space, 30, 280-297.

41. Petty, R.E.,Wheeler, S.C., \& Tormala, Z.L. (2009). Persuasion and attitude change. In T. Millon \& M. J. Lerner, (Eds.), Comprehensive handbook of psychology ( $2^{\text {nd }}$ edition). New York: John Wiley \& Sons.

42. Putnam, L., \& Mumby. D.K. (1993). Organizations, emotions and the myth of rationality. In S. Fineman (Ed.), Emotion in organizations. Sage: London.

43. Roberts, M., Wants, W., \& Tzong-Horng, D. (2002). Agenda setting and issue salience online. Communication Research, 29(4), 452-465.

44. Rutkin, A. (2015). 'No empathy? Fake it'. New Scientist, 9 May, 20-21.

45. Salwen, M.E., Garrison, B.G., \& Driscoll, P.D. (Eds.) (2005). Online news and the Public. Mahwah, NJ.: Lawrence Erlbaum Associates.

46. Tan, Y., \& Weaver, D.H. (2013). Agenda diversity and agenda setting from 1956 to 2004. Journalism Studies, 14(6), 773-789.

47. Taylor, M., \& Kent, M.L. (2014). Dialogic engagement: Clarifying foundational concepts. Journal of Public Relations Research, 26(5), 384-398.

48. Tench, R., Sun, W., \& Jones, B. (2014). Introduction: CSR Communication as an emerging field of study. In R. Tench, W. Sun, \& B. Jones (Eds.). Communicating corporate social responsibility: Perspectives and practice (pp. 3-25). Howard House: Emerald.

49. Tench, R., \& Moreno, A. (2015). Mapping communication management competencies for European practitioners. Journal of Communication Management, 19(1), 39 - 61.

50. Topic, M., \& Vasiljevic, S. (2011). Work Package 7 - Identity construction programs of the state and the EU: case study phase III: Citizens and modernities: Between national and European paths in Croatia. Project report submitted to the European Commission inside FP7 Identities and Modernities project (SSH-CT-2009-215949) in February, 2011.

51. Turner, J.H., \& Stets, J.E. (2005). The sociology of emotions. New York: Cambridge University Press.

52. Weiss, C. (1974). What America's leaders read. Public Opinion Quarterly, 38, 1-22.

53. Winter, J., \& Eyal, C. (1981). Agenda setting for the civil rights issue. Public Opinion Quarterly, 45, 376-383.

54. Wodak, R. (1999). The discursive construction of national identity. Edinburgh: Edinburgh University Press.

55. Yeomans, E. (2013). Exploring professional relationships in public relations: An emotional labour perspective. (Unpublished doctoral thesis). Leeds: Metropolitan University, Leeds, UK. 